(2.9\%) straight. 918/1186 (77.4\%) were HIV-negative, 42/1186 (3.5\%) HIV-positive, 188/1186 (15.9\%) never tested, and 38/ 1186 (3.2\%) unknown status. The median age of first sexual behaviour with another man was 17.6 years (6-41). The median age of disclosure of sexuality to: family is 18 years $(8-45)$ and friends 17 years (11-41); sexual health services 892/1186 $(66.6 \%)=19.0$ years $(14-54)$; and to primary care $522 / 1186$ $(44 \%)=21.2$ years $(13-54)$. There is a difference between age of first sexual experience and disclosure to primary care of 3.6 years.

Discussion/conclusion Delayed disclosure to healthcare professionals of sexuality by MSM is likely to impede the uptake of important health interventions in MSM.

\section{P065 LACK OF EXPOSURE TO GENITOURINARY MEDICINE (GUM) IS LEADING TO A RECRUITMENT CRISIS}

${ }^{1,3}$ Anna Hartley ${ }^{*},{ }^{2-4}$ Daniel Richardson. ${ }^{1}$ Barts Health NHS Trust, London, UK; ${ }^{2}$ Brighton \& Sussex University NHS Trust, Brighton, UK; ${ }^{3}$ British Association for Sexual Health and HIV; ${ }^{4}$ Brighton \& Sussex Medical School, Sussex, UK

\subsection{6/sextrans-2016-052718.119}

Background In 2015, genitourinary medicine (GUM) filled 46\% of its national training numbers. Reasons for low recruitment are unclear. In February, GUM exhibited at the Royal College of Physicians (RCP) Medical Careers Day attended by undergraduates (UGs) and junior doctors (JDs).

Aim We aimed to assess the factors that attract and deter delegates from choosing a career in GUM.

Methods A survey was conducted amongst delegates who visited the GUM stall at the Careers Day.

Results 93\% (25/27) of delegates who visited the stall completed the survey (14 UGs, 8 foundation year (FY) doctors, 3 other). $33 \%(8 / 24)$ would like a career in GUM (54\% (13/24) not sure; $13 \%(3 / 24)$ were not interested in GUM). 92\% (23/25) would like/have liked a rotation in GUM as a JD. 76\% (19/25) were exposed to GUM in medical school (86\% FYs, 50\% UGS). One delegate had done a rotation in GUM as a FY. The table shows the main factors that attract delegates to or deter them from a career in GUM:

\begin{tabular}{llll}
\multicolumn{2}{l}{ Abstract P065 Table 1 } \\
\hline Attracts & $\begin{array}{l}\text { Number of } \\
\text { delegates }\end{array}$ & Deters & $\begin{array}{l}\text { Number of } \\
\text { delegates }\end{array}$ \\
\hline $\begin{array}{l}\text { "Variety/interesting } \\
\text { speciality" }\end{array}$ & 11 & $\begin{array}{l}\text { Lack of exposure to } \\
\text { GUM }\end{array}$ & 5 \\
Work-life balance & 7 & $\begin{array}{l}\text { Lack of inpatient } \\
\text { work }\end{array}$ & 3 \\
Research opportunities & 4 & & \\
HIV & 4 & & \\
\hline
\end{tabular}

Conclusion This survey shows that there is interest in GUM at UG/JD level. A variety of factors appealed to delegates, with fewer deterrents, of which "lack of exposure" predominated. Delegates would like GUM rotations as JDs. Optimising exposure to GUM within medical schools and JD rotations should be a priority in order to attract trainees to GUM.
P066 TRANSMISSION OF NEISSERIA GONORRHOEAE AMONG MEN WHO HAVE SEX WITH MEN: AN ANATOMICAL SITE-SPECIFIC MATHEMATICAL MODEL AND IMPACT OF MOUTHWASH

1,2 Lei Zhang ${ }^{*}$, ${ }^{3}$ David Regan, ${ }^{1,2}$ Eric Chow, ${ }^{1,2}$ Vincent Cornelisse, ${ }^{5}$ Manoj Gambhir, 1,2Jane Hocking, ${ }^{1}$ Christopher Fairley. ${ }^{1}$ Melbourne Sexual Health Centre, Melbourne, Australia; ${ }^{2}$ Central Clinical School, Faculty of Medicine, Monash University, Melbourne, Australia; ${ }^{3}$ Kirby Institute, Faculty of Medicine, University of New South Wales, Sydney, Australia; ${ }^{4}$ Melbourne School of Population and Global Health, University of Melbourne, Melbourne, Australia; ${ }^{5}$ School of Public Health and Preventive Medicine, Faculty of Medicine, Monash University, Melbourne, Australia

\subsection{6/sextrans-2016-052718.120}

Background/introduction Epidemiological data suggest that kissing may play a significant role in gonorrhoea transmission.

Aim(s)/objectives We developed a transmission model to explain anatomical site-specific prevalence of gonorrhoea among Australian men who have sex with men (MSM) and evaluate the population-level impacts of screening and the use of mouthwash as interventions in reducing its transmission.

Methods We constructed a gonorrhoea transmission model to estimate the per-act transmission probability. Using Monte-Carlo simulations, we constructed hypothetical scenarios to evaluate its population-level impacts.

Results We have previously reported the prevalence of pharyngeal, anal and urethral gonorrhoea as being 10.6\% (95\%CI 8.1$12.2 \%), 8.6 \%(6.7-10.4 \%)$ and $0.17 \%(0.02-0.24 \%)$, respectively, in Australian MSM. Calibrated to these data, the modelestimated per-act transmission probability for gonorrhoea was high for transmission from urethra-to-anus (46.0\% [41.752.6\%]) and from-urethra to-pharynx (49.6\% [46.7-53.8\%]). Although pharynx-to-pharynx transmission through kissing has only a transmission probability of $17.4 \%$ (16.0-21.0\%), it accounts for nearly three quarters of the annual incident cases (74.6\% [70.0-82.4\%]). A substantial increase in gonorrhoea screening from the current $40 \%$ to $100 \%$ may only halve gonorrhoea prevalence in MSM. In contrast, the use of mouthwash with moderate efficacy (extra 1\% bacterial load reduction/use) would further reduce the corresponding site prevalence to $2.4 \%$ $(1.8 \%-3.7 \%), 2.2 \% \quad(1.6-3.2 \%)$ and $0.02 \% \quad(0.01-0.03 \%)$, whereas a high efficacy (extra $1.5 \%$ reduction/use) may achieve a scenario of close to elimination.

Discussion/conclusion Our results suggests that kissing may be the key driver of community prevalence. If antibacterial mouthwash is effective and widely used, it may contribute to controlling the gonorrhoea epidemic.

\section{P067 WHY DON'T PEOPLE WITH GENITO-URINARY SYMPTOMS GO TO SEXUAL HEALTH CLINICS? A MIXED METHODS STUDY ABOUT MEANINGS OF SYMPTOMS AND CARE-SEEKING USING THE THIRD NATIONAL SURVEY OF SEXUAL ATTITUDES AND LIFESTYLES (NATSAL-3)}

${ }^{1}$ Fiona Mapp*, ${ }^{1}$ Ford Hickson, ${ }^{2}$ Cath Mercer, ${ }^{1}$ Kaye Wellings. 'London School of Hygiene \& Tropical Medicine, London, UK; ${ }^{2}$ University College London, London, UK

\subsection{6/sextrans-2016-052718.121}

Background/introduction There are both individual and public health benefits in people responding to genito-urinary symptoms effectively. Sexual health clinics are best equipped for managing symptoms but not everyone with symptoms chooses to attend. 
Aim(s)/objectives To examine the prevalence and meanings of genito-urinary symptoms and the impact on non-attendance at sexual health clinics among people in Britain.

Methods An explanatory sequential mixed methods study design was used to estimate symptom and clinic non-attendance prevalences using data from 8,947 sexually-experienced women and men aged 16-44 years who participated in Britain's third National Survey of Sexual Attitudes and Lifestyles (Natsal-3). We conducted follow-up semi-structured interviews with Natsal-3 participants $(n=27)$ who reported current or recent symptoms and had never attended a clinic, in order to explore STI perceptions, symptom meanings and care-seeking behaviour.

Results Prevalence of experiencing symptom(s) in the last month was 21.6\% (95\% CI 20.4-22.9\%) among women and 5.6\% (95\% CI 4.9-6.6\%) among men, of whom $86.3 \%$ (95\% CI 84.2-88.1) reported not having attended a sexual health clinic in the past year. Bodily changes were not always viewed as symptoms and perceived potential causes were diverse, causing strong emotional responses. Individuals normalised, concealed and/or distanced their experiences from STIs. GPs were the preferred service provider although not all participants perceived a need for care.

Discussion/conclusion Symptoms are more commonly reported by women although both women and men may benefit from interventions targeting symptom normalisation and concealment. Good links between services will facilitate efficient and appropriate care-seeking and service delivery.

\section{P068 INEQUALITIES IN SEXUALLY TRANSMITTED INFECTION RISK AMONG BLACK AND MINORITY ETHNIC MEN WHO HAVE SEX WITH MEN IN ENGLAND}

Hamish Mohammed*, Martina Furegato, Gwenda Hughes. Public Health England, London, UK

\subsection{6/sextrans-2016-052718.122}

Background/introduction Sexually transmitted infection (STI) diagnoses are increasing in men who have sex with men (MSM) in England. While black and minority ethnic (BME) populations bear a disproportionate burden of STIs overall, it is unclear whether this inequality persists among MSM.

Aim(s)/objectives To assess the likelihood of an STI diagnosis among BME MSM relative to other MSM attending genitourinary medicine (GUM) clinics in England.

Methods We included data from the GUM clinic activity dataset (GUMCADv2), the national STI surveillance system in England. All attendances by MSM in 2014 were analysed using univariate and multivariable generalised estimating equations logistic regression. Separate models, adjusted for age, sexual orientation (homosexual/bisexual), residence (London/non-London), arealevel deprivation, HIV positivity and history of HIV testing in the past year, were run for each STI.

Results BME men accounted for 5.6\% of the 326,820 attendances by MSM in 2014. An STI was diagnosed at $12.5 \%$ of attendances by MSM, ranging from $11.1 \%$ in Asian non-Indian/ Pakistani/Bangladeshi to $17.7 \%$ in mixed white and black African MSM. Compared to white British MSM, black Caribbean MSM were most likely to be diagnosed with chlamydia (aOR [95\% $\mathrm{CI}]: 1.34$ [1.18-1.52]) and rectal gonorrhoea (1.31 [1.08-1.60]), while those of mixed white and black African ethnicity were most likely to be newly diagnosed with HIV (1.90 [1.14-3.17]).
Discussion/conclusion Among MSM attending GUM services, BME MSM are most likely to be diagnosed with bacterial STIs and HIV. Culturally appropriate prevention messages must be developed to address this inequality and reduce the higher burden of STIs among BME MSM.

\section{P069 WHAT IMPACT HAS TENDERING HAD ON TRAINEES? THE RESULTS OF A NATIONAL SURVEY OF TRAINEES AND NEWLY APPOINTED CONSULTANTS BY BASHH TRAINEES COLLABORATIVE FOR AUDIT, RESEARCH AND QUALITY IMPROVEMENT PROJECTS}

${ }^{1}$ Helen Wiggins, ${ }^{2}$ Anna Hartley*${ }^{*}{ }^{3}$ Nadia Ahmed, ${ }^{4}$ Emily Clarke, ${ }^{4}$ Elizabeth Foley, ${ }^{5,6}$ Elizabeth Carlin, ${ }^{3}$ Laura Waters. ${ }^{1}$ Chelsea and Westminster Hospital NHS Foundation Trust, London, UK; ${ }^{2}$ Barts Health NHS Trust, London, UK; ${ }^{3}$ Central and North West London NHS Foundation Trust, London, UK; ${ }^{4}$ Solent NHS Trust, Hampshire, UK; ${ }^{5}$ Sherwood Forest Hospitals NHS Foundation Trust, Nottinghamshire, UK; ${ }^{6}$ Nottingham University Hospitals NHS Trust, Nottinghamshire, UK

\subsection{6/sextrans-2016-052718.123}

Background/introduction In April 2013, local authorities gained responsibility for commissioning services for sexual health in England. With many services going to tender and resultant change in services or service provider, there is anecdotal evidence that this has impacted on the education, training and morale of genitourinary medicine (GUM) trainees.

Aim(s)/objectives To evaluate the impact of tendering on GUM trainees.

Methods An electronic survey designed by the British Association for Sexual Health and HIV Trainees' Collaborative for Audit, Research and Quality Improvement Projects (T-CARQ) was distributed to GUM trainees and newly appointed consultants.

Results 82 individuals responded, (74\% GUM trainees, 25\% newly appointed consultants, 1\% Locum appointed for Service). $63 \%(45 / 72)$ had experience of training within a service which was being tendered. Of these, 59\% (24/41) felt their training was not considered and 20\% (8/41) felt that it was. 44\% (18/41) felt adequately supported. $30 \%(12 / 40)$ reported active participation in the tendering process. On a scale of 0 (no impact) to 5 (major impact), the median score for impact of tendering on training was 2 . The positive/negative impact of tendering on different training elements was rated; other than management experience the overall impact on all parameters was negative namely morale, senior support and education.

Discussion/conclusion This survey describes the variable impact of service tendering on GUM training. Our recommendations for maintaining training standards despite tendering include: actively involving trainees and education partners, inclusion of specialist GUM training in service specifications, development of guidance for commissioners and services for the management of GUM training within tendering.

\section{P070 'CHEMSEX' WITHIN MEN WHO HAVE SEX WITH MEN (MSM): HOW BIG IS THE PROBLEM OUTSIDE MAJOR CONURBATIONS?}

\footnotetext{
${ }^{1,2}$ Helen Wiggins, ${ }^{2}$ Helen Mebrahtu* ${ }^{*}{ }^{1}$ Ann Sullivan, ${ }^{2,3}$ Nigel Field, ${ }^{2}$ Gwenda Hughes. ${ }^{1}$ Chelsea and Westminster Hospital NHS Foundation Trust, London, UK; ${ }^{2}$ Public Health England, London, UK; ${ }^{3} \mathrm{UCL}$ Research Department of Infection and Public Health, London, UK
}

10.1136/sextrans-2016-052718.124 